\title{
DIRECT MEASUREMENT OF CHOLESTEROL ABSORPTION VIA THE THORACIC DUCT IN MAN*
}

\author{
By LEON HELLMAN, E. L. FRAZELL aNd R. S. ROSENFELD \\ (From the Sloan-Kettering Institute for Cancer Research and the Memorial Hospital, \\ Nea' York, N. Y.)
}

(Submitted for publication February 26, 1960; accepted March 25, 1960)

The route of absorption of steroids from the gastrointestinal tract seems to be largely determined by the chemical nature of the compounds. Methyl testosterone (1), $17 \alpha$-methyl estradiol (2), and cortisone acetate (3) are absorbed in the rat by way of the portal circulation. Studies from this laboratory in human subjects showed that testosterone, cortisol, cortisone acetate, and corticosterone are also absorbed in this manner and are virtually absent from the lymph (4). In contrast, absorption of cholesterol into lymph of the rat $(5,6)$ and $\log (7)$ accounts for essentially all of the sterol that enters these species from the diet. Although it might be anticipated from these animal studies and from the nonpolar nature of the molecule that cholesterol would be absorbed via the lymph in human subjects, it was of interest to test this directly, since some aspects of steroid metabolism in the laboratory animal are different from those observed in man $(8-10)$. By means of cannulation of the thoracic duct and the administration of labeled cholesterol, it has been possible for the first time to study directly the absorption and esterification of cholesterol in man. These studies have demonstrated that dietary cholesterol is largely absorbed through the lymphatics and that the major portion is esterified during the absorptive process.

\section{MATERIAL AND METHODS}

The clinical data concerning the subjects are given in Table I. A polyethylene catheter was inserted into the left thoracic duct at operation as described previously (4). The lymph was continuously collected from the thoracic duct cannula at predetermined time intervals and blood samples were withdrawn periodically. The pa-

* This investigation was supported by a grant from the American Cancer Society: Contract AT30-1 910 with the United States Atomic Energy Commission; and research grants from the National Heart Institute ( H-2157) and the National Cancer Institute (CY-3207). Bethesda, Md. tients were maintained in fluid and protein balance by the infusion of appropriate quantities of electrolytes and salt-free albumin during the period that large volomes of lymph were being removed.

Cholesterol-14, 15- $\mathrm{H}^{3}$ and sodium acetate-2- $\mathrm{C}^{14}$ were given to 1 subject while cholesterol-4- $\mathrm{C}^{1+}$ was administered to 3 other patients. The radioactive compounds were given orally and the amounts are listed in Table I. Radiochemically pure free and ester cholesterol were isolated from plasma and red cells by methods that have been described (11). Free and ester cholesterol were also obtained from lymph by the same procedures, but in a few instances lymph was deproteinized with acetonealcohol, the solution was concentrated, and the portion of the residue that was soluble in petroleum ether was chromatographed on alumina to isolate free cholesterol and cholesterol esters.

$\mathrm{C}^{\mathbf{1 4}}$ radioactivity was determined by counting cholesterol digitonide mounted on stainless steel planchets in a windowless gas-flow counter (12). $C^{14}$ activity was also measured by combustion of cholesterol digitonide and counting the carbon dioxide (13): tritium was determined in the same sample by reducing the water produced by the combustion to hydrogen and counting in the proportional region (14).

\section{RESULTS}

Figure 1 shows the specific activity of lymph and plasma cholesterol- $\mathrm{C}^{14}$ observed over 75 hours following the oral administration of cholesterol$4-\mathrm{C}^{14}$ to Subject W.I. The lymph free and ester cholesterol attained a peak specific activity at 8 hours. It should be noted that ester cholesterol appeared promptly in the lymph although free cholesterol was administered. The specific activity of the lymph ester cholesterol is equal to or greater than that of the free cholesterol, especially during the first 30 hours of the experiment. Cholesterol analyses of this lymph at various intervals showed that an average of 65 per cent of the sterol was esterified (Table I). Since there was a greater total amount of ester cholesterol of high specific activity in the lymph of Subject W.I., esterification of cholesterol must have been achieved in the intestinal mucosa. The spe- 
TABLE I

Clinical data and administration of radioactive compounds

\begin{tabular}{|c|c|c|c|c|c|c|c|}
\hline \multirow[b]{2}{*}{ Subject, age* } & \multirow{2}{*}{$\begin{array}{l}\text { Diagnosis, } \\
\text { cancer }\end{array}$} & \multicolumn{2}{|c|}{$\begin{array}{c}\text { Lymph } \\
\text { cholesterol (avg.) }\end{array}$} & \multirow{2}{*}{$\begin{array}{l}\text { Lymph } \\
\text { flow }\end{array}$} & \multirow{2}{*}{$\begin{array}{l}\text { Compound } \\
\text { administered }\end{array}$} & \multirow[b]{2}{*}{ Wt. of comp. } & \multirow[b]{2}{*}{ Radioactivity } \\
\hline & & Total & Ester & & & & \\
\hline & \multirow{6}{*}{$\begin{array}{c}\text { Larynx } \\
\text { (laryngectomy) } \\
\text { Tonsil } \\
\text { Tonsil } \\
\text { Lip }\end{array}$} & $m g \%$ & $\%$ & $m l / h r$ & & $m g$ & $d p m+\times 10^{-7}$ \\
\hline W.I., 55 & & 80 & 68 & 48 & Cholesterol-4-C $\mathrm{C}^{14}$ & 13.6 & 14.3 \\
\hline M. 0.70 & & 60 & 55 & 59 & Cholesterol-4_- 14 & 410 & 1 \\
\hline P.U. 70 & & & J & 58 & Cholesterol-4-C 14 & 112 & $\begin{array}{r}4.4 \\
118\end{array}$ \\
\hline W.E., 55 & & 62 & 52 & 70 & Cholesterol-14, 15- $\mathrm{H}^{3}$ & 7.5 & 21.8 \\
\hline & & & & & Sodium acetate-2-C & 16.9 & 44.0 \\
\hline
\end{tabular}

* All were men.

$\dagger$ Disintegrations per min.

cific activity relationships of free and ester lymph cholesterol can perhaps be explained by the experiments of Swell and colleagues (15) who fed cholesterol-4- $\mathrm{C}^{14}$ to rats and found that the radioactive cholesterol present in the intestinal mucosa was largely in the free form. This would suggest that esterification occurs in conjunction with the transport of the newly absorbed cholesterol from the cells of the mucosa into the lymph. Therefore, the relative quantity of the mucosal cholesterol which is esterified would largely determine the proportion of lymph free and ester cholesterol as well as their specific activities.

During the period of lymph collection, over 27 per cent of the radioactive cholesterol was absorbed by this route (Table II). The lower set of curves in Figure 1 shows the specific activity of plasma cholesterol observed simultaneously with that in lymph. During the period of active absorption into the lymph, the plasma cholesterol attained a specific activity of approximately 1.5

TABLE II

Distribution of radioactivity from labeled cholesterol

\begin{tabular}{|c|c|c|c|}
\hline Subject, age & $\begin{array}{l}\text { Max. incorp. } \\
\text { radioactivity } \\
\text { into plasma }\end{array}$ & $\begin{array}{l}\text { Cumulative } \\
\text { radioactivity } \\
\text { in lymph }\end{array}$ & $\begin{array}{c}\text { Cumulative } \\
\text { radioactivity } \\
\text { in feces }\end{array}$ \\
\hline $\begin{array}{l}\text { W.I., } 55 \\
\text { M.O., } 70 \\
\text { P.U., } 70 \\
\text { W.E., } 55\end{array}$ & $\begin{array}{c}\%^{*} \\
1.0[72]^{\dagger} \\
0.3[7]^{\ddagger} \\
2.0[24] \\
1-2[10]_{+}^{+}\end{array}$ & $\begin{array}{c}\% \\
27.4[72] \\
4.5[44] \\
27.1[84] \\
7-14[10]\end{array}$ & $42[144]$ \\
\hline
\end{tabular}

* Percentage of administered radioactive cholesterol.

+ Elapsed time in hours, [ ].

¥ Calculated from specific activity of plasma cholesterol and size of plasma and liver cholesterol pool (16). All other values by direct measurement of total radioactivity.

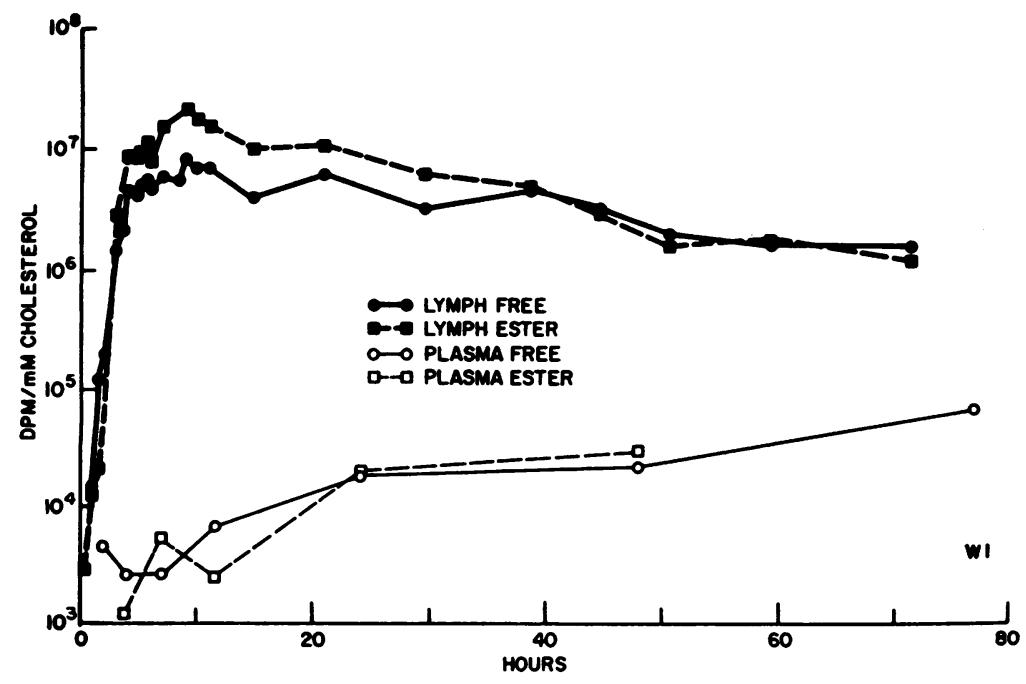

Fig. 1. INCORPORATION OF ORAL ChOLESTEROL-4-C14 INTO LYMPH AND Plasma cholesterol; Subject W.I. 
per cent of that in the lymph. The low value for the specific activity of plasma cholesterol is due to the fact that the principal lymphatic outflow from the intestine was diverted from the body through the cannula and only small quantities of lymph could reach the circulation through collateral channels. The labeled cholesterol in this small quantity of lymph was then diluted with the pre-existing unlabeled circulating sterol pool to yield plasma cholesterol of low specific activity. The total quantity absorbed through these collateral channels approximated 1 per cent of the administered radioactivity. These values are given in Table II and can be calculated from the specific activity of plasma cholesterol and the size of the plasma and liver cholesterol pool which are known to be in isotopic equilibrium (16).

The rate curves of the specific activity of free and ester cholesterol in the plasma and lymph of Subject M.O. are presented in Figure 2. The specific activity of lymph ester cholesterol during the time of maximal absorption was about 1.5 times that of free sterol. It can be seen in Figure 2 that the specific activity of plasma sterol was less than 1 per cent of that of lymph cholesterol. About 0.3 per cent of the radioactivity was present in the circulation as compared with 4.5 per cent which appeared in the lymph that was drained off (Table II).

In Subject P.U., who also received cholesterol4- $\mathrm{C}^{14}$, the specific activity of lymph free cholesterol was higher than that of ester cholesterol, but both of these were over 50 times the

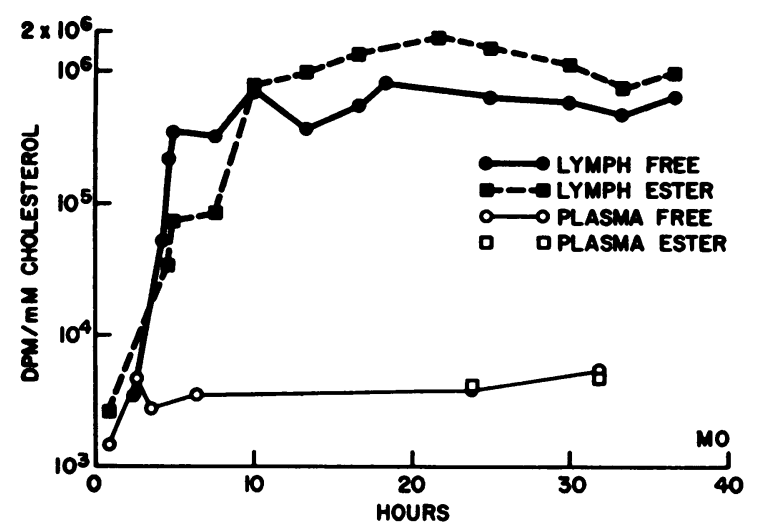

Fig. 2. InCORPoration OF ORAL ChOLESTEROL-4-C ${ }^{14}$ into LYMPH AND PLASMA Cholesterol; Subject M.O.

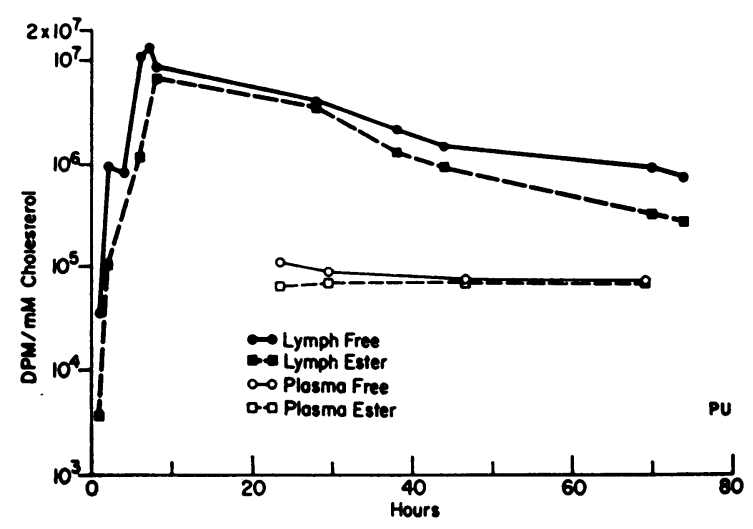

Fig. 3. InCORporation OF ORAL CHOLESTEROL-4-C $\mathbf{1 4}^{4}$ into Lymph and Plasma Cholesterol; Subject P.U.

specific activity of plasma sterol, as can be seen in Figure 3. Approximately 27 per cent of the administered dose was accounted for in the lymph, which is over 10 times that in the circulation (Table II). In this subject where measurement of fecal radioactivity was practicable, 42 per cent was eliminated by this route after six days.

Subject W.E. was given cholesterol-14, 15- $\mathrm{H}^{3}$, and during the 10 hours in which observations were made, he absorbed approximately 10 per cent of the radioactive cholesterol in the intestinal lymph. Collection of lymph had to be discontinued at this time due to blockage in the cannula, but it can be seen in Figure 4 that the sustained peak specific activity of lymph free cholesterol indicates that cholesterol absorption continued for at least this period of time. The specific activity of cholesterol- $\mathrm{H}^{3}$ in the plasma was approximately 0.1 per cent of that in the lymph and from this it can be calculated that 0.2 per cent of the dose appeared in the circulation (Table II).

Subject W.E. received $\mathrm{C}^{14}$-acetate simultaneously with the oral dose of tritium-labeled cholesterol. This procedure permitted a study of lymphatic transport of endogenously synthesized cholesterol in order to provide comparison with the data concerning exogenous cholesterol. Figure 5 shows the specific activity of lymph and plasma cholesterol of biosynthetic origin in this subject. The free cholesterol- $\mathrm{C}^{\mathbf{1 4}}$ of plasma has the highest specific activity through the 10-hour period of observation. The lymph free cholesterol specific activity paralleled that of the plasma but was only about one-fifth of the value. Both the 
lymph and plasma ester cholesterol have similar specific activities except for the two earliest values of lymph ester cholesterol at 26 minutes and 55 minutes after administration of the precursor; these values were higher than corresponding plasma ester cholesterol specific activities. Since the only material of high specific activity available at this time is the plasma free cholesterol, it is tempting to assume that the two early samples of lymph ester cholesterol were derived by the esterification of plasma free cholesterol in the intestine. The shape and magnitude of $\mathrm{C}^{14}$-labeled plasma free and ester cholesterol radioactivity curves are generally similar to those of intact subjects. This would be expected if the sodium acetate-2- $\mathrm{C}^{14}$ fed to the patients with cannulated thoracic ducts was absorbed into the portal circulation and transported to the site of cholesterol synthesis by a route not involving lymph. Measurement of the total radioactivity in the lymph and plasma of Subject W.E. showed that $20 \mathrm{~min}$ utes after ingestion of the labeled sodium acetate, the radioactivity in plasma was seven times greater than that in an equal volume of lymph; the shape of the curves shows that this difference was much larger in the initial moments of the experiment (Figure 6).

The specific activity of endogenous ( $\mathrm{C}^{14}$ ) cholesterol in the lymph was lower than the corresponding values in plasma and could be due to three factors : 1) dilution of lymph cholesterol by unlabeled sterol from the intestinal mucosa at the start of the experiment; 2) continuous dilution by

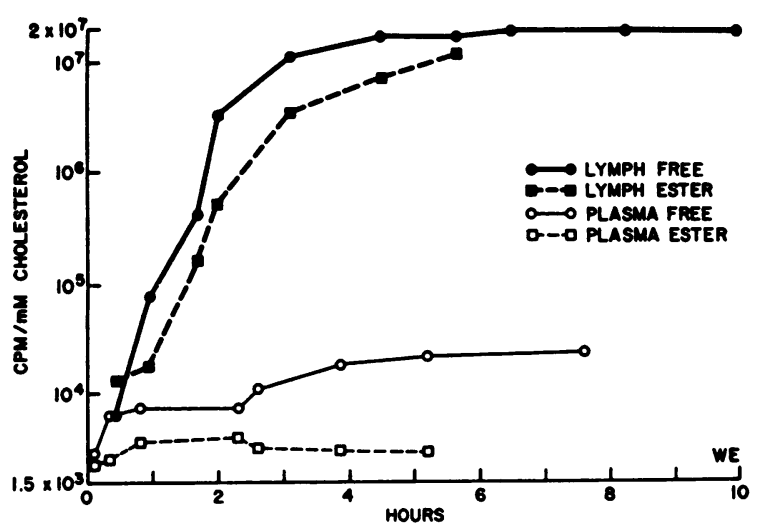

Fig. 4. INCORPORATION OF ORAL CHOLESTEROL-14, 15- $\mathrm{H}^{3}$ INTO LYMPH AND PLASMA ChOLESTEROL; SUBJECT W.E.

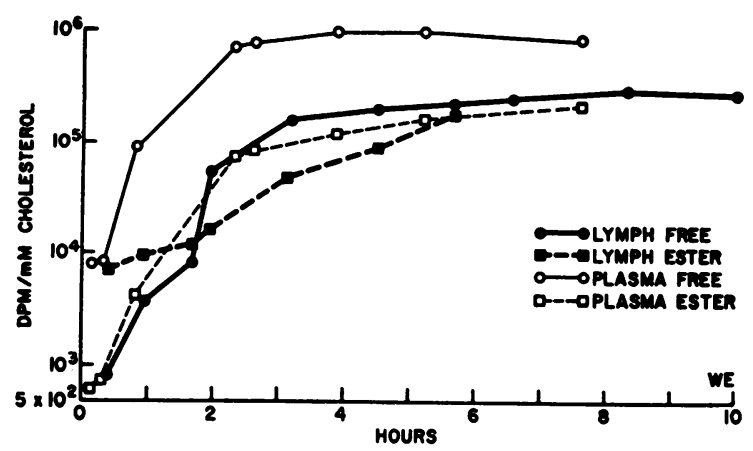

Fig. 5. InCORPoration OF ORAL ACETATE-2-C I $^{\mathbf{4}}$ INTO LYMPH ANd Plasma cholesterol, Subject W.E.

dietary cholesterol ; 3) the possible operation of an ultrafiltration process between plasma and lymph which might remove lipoprotein containing newly labeled cholesterol.

\section{DISCUSSION}

1. Absorption of cholesterol. These studies on the direct measurement of cholesterol absorption into lymph in man are in substantial agreement with earlier results obtained in animals. The data indicate that the lymphatic system of the intestine, rather than the portal circulation, is the route through which cholesterol is absorbed. From 4 to 27 per cent of the orally administered cholesterol was absorbed in patients in this study over periods of time varying from 8 to 80 hours. In rats, from 2 to 49 per cent of the administered dose was absorbed $(6,17-19)$, and Blomstrand and Ahrens calculated that 20 per cent of the administered cholesterol was absorbed in a patient with chyluria (20). This relatively wide range of cholesterol absorption agrees with the range of 8 to 33 per cent previously reported from this laboratory in intact subjects (21). These variations might be anticipated because of the many factors involved in cholesterol absorption, including the amount of cholesterol $(22,23)$, fat and fatty acids $(24,25)$, presence of bile salts (17, $19,26,27)$, pancreatic secretion $(17,25,28)$, and other sterols (23).

The amount of labeled cholesterol which appeared in the plasma was only a small fraction of the amount in the lymph. This result is consistent with the conclusion that lymph is the principal, if not the only, route for the transport of newly absorbed cholesterol from the intestine. It is to be 
anticipated that small amounts of cholesterol would enter into the circulation despite the diversion of the major portion of the intestinal lymph from the body. It is known from anatomical and radiographic studies that a right thoracic duct as well as other auxiliary lymphatic channels transport a significant amount of lymph in many subjects (29). However, there is little question that the left thoracic duct was the main route of absorption in the four subjects of this investigation. It is of interest that substances of similar formal structure, but differing in polarity, such as cholesterol and steroid hormones (testosterone, cortisol) are absorbed through different routes (4).

2. Esterification of lymph cholesterol. Although free cholesterol was administered, most of the newly absorbed cholesterol in lymph was esterified. From 50 to 80 per cent of the radioactive cholesterol in lymph was present as ester. which is quite similar to values observed in rats $(6,17$, 22, 30) and $\operatorname{logs}(7)$. Animal stuclies indicate that esterification with fatty acid occurs before the appearance of newly absorbed cholesterol in the lymph $(5,22-25,27)$. Cholesterol in the free form appears to be the material actually transported from the intestinal lumen into the mucosa. Esterification of the free sterol then takes place in the mucosa during transport into the lymph $(15,27)$. In contrast. Favarger and Metzger report that, in the $\log$ and rat, free cholesterol was absorbed into the lymph and was esterified by esterases present in that fluid (31). in Figure 5, which illustrates the incorporation of

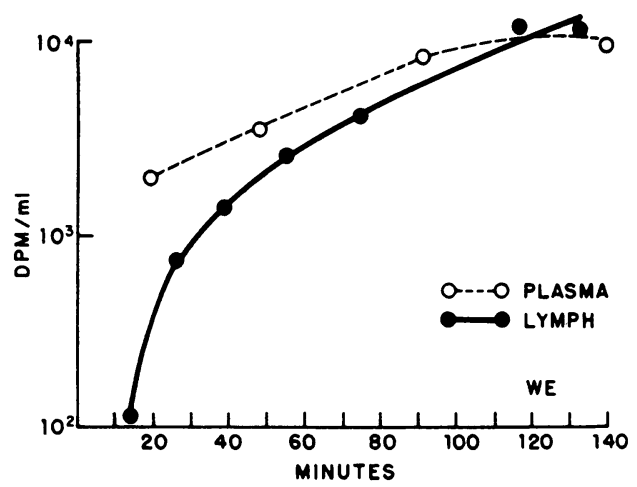

Fig. 6. Total radioactivity in Lymph aNd plasma AFTER ORAL ADMINistration OF ACETATE-2-C ${ }^{14}$; SubJECT W.E. acetate into lymph and plasma cholesterol, the lymph ester cholesterol has a greater specific activity than does the corresponding lymph free cholesterol during the first two hours. Since plasma free cholesterol is initially labeled in the biosynthetic process, it seems probable that the newly synthesized radioactive cholesterol of the plasma may be esterified in the cells of the intestine and directly thereafter appears in the lymph as ester cholesterol. An alternative explanation is that some cholesterol may be biosynthesized from acetate in the intestinal wall and esterified as it appears in the lymph. In the intestinal lumen, the cholesterol is composed of a mixture of dietary sterol, cholesterol secreted from the intestinal wall. and biliary cholesterol secreted from the liver. It is realized that this is not a homogenous pool of cholesterol but one in which the relative cholesterol contribution from each source might vary; indeed, it is possible that unknown factors may be operative which permit cholesterol from each source to be absorbed or reabsorbed at different rates. Nevertheless, this study and others cited show that cholesterol in this mixture is largely esterified during absorption. Therefore, there appear to be at least two sources of ester cholesterol in the lymph: 1) from the intestinal lumen; 2) from the intestinal mucosa where the cholesterol may originate either by ultrafiltration from the plasma or by biosynthesis from endogenous precursors at this site. Thus cholesterol from various origins which is esterified in the intestinal mucosa may serve as a significant portion of the ester cholesterol moiety of the circulating lipoprotein. These considerations focus attention on possible alterations of the metabolic activity of intestinal mucosa in addition to the well recognized disturbances of liver function which produce changes in level of circulating cholesterol ester.

3. Clearance of lymph cholesterol. The extent of intestinal cholesterol esterification in humans may also be germane to alterations in cholesterol metabolism observed in hyperlipemic-hypercholesterolemic subjects. From our previous studies (21) on absorption of cholesterol in normocholesteremic suljjects, it is known that the specific activity of plasma ester cholesterol was less than that of plasma free cholesterol during the first two days following the oral administration of labeled 
sterol. The actual ratio of the specific activities of plasma ester to free cholesterol in normocholesterolemic subjects about 24 hours after the radioactive dose was 0.7 to 0.8 . However, in hyperlipemic subjects, the same ratio was 1.6 to $2.5 .^{1}$ If it were assumed that all of the labeled ester and free cholesterol absorbed in lymph were retained in the plasma and mixed indistinguishably with plasma cholesterol, it is possible to calculate a resultant specific activity ratio. In the normocholesteremic subjects this would yield a value of ester to free of about 2.0 (assuming lymph cholesterol to be about 80 per cent ester) in contrast to the observed ratio of 0.7 to 0.8 . However, the calculated ratio is close to the range of 1.6 to 2.5 observed in the plasma of hyperlipemic subjects. It should be noted that the amount of free and ester cholesterol absorbed after a tracer dose into lymph is known only for normocholesteremic subjects and might be different in the hyperlipemic. However, these relations strongly suggest that the normocholesteremic might be able to clear a portion of the newly absorbed ester cholesterol from the plasma, whereas this mechanism might not be fully operative in the hyperlipemic patient. These considerations point to the desirability of additional studies of the intestinal esterification mechanism as well as of the ester removal mechanism for the fuller understanding of pathologic hyperlipemic states.

\section{SUMMARY}

1. Cholesterol-14, 15- $\mathrm{H}^{3}$ and sodium acetate2-C ${ }^{14}$ were orally administered to one subject while cholesterol-4-C $\mathrm{C}^{\mathbf{1 4}}$ was given to three other subjects. These individuals had cannulas in the thoracic duct so that lymphatic absorption of cholesterol could be directly studied.

2. The amount of labeled cholesterol absorbed into the lymph varied from 4 to 27 per cent of the administered dose. The major portion of this absorbed cholesterol appeared in the lymph in esterified form.

3. A minor role in cholesterol absorption by the collateral lymphatics was evidenced by the low level of radioactivity in plasma cholesterol.

\footnotetext{
1 Calculated from data taken from subjects in Reference 21 and other unpublished data from this laboratory.
}

4. Although sodium acetate is not absorbed in the human by way of the lymph system, the amount incorporated into circulating cholesterol was approximately that found in intact subjects.

5. The absorption and esterification of cholesterol as well as the possible role of cholesterol metabolism in the intestine and lymph have been discussed with reference to pathologic hyperlipemia.

\section{ACKNOWLEDGMENT}

The support and interest of Dr. T. F. Gallagher in this investigation are gratefully acknowledged.

\section{REFERENCES}

1. Hyde, P. M., Doisy, E. A., Jr., Elliott, W. H., and Doisy, E. A. Absorption of enterally administered $17 \alpha$-methyl- $\mathrm{C}^{14}$-testosterone and its metabolites. J. biol. Chem. 1954, 209, 257.

2. Bocklage, B. C., Nicholas, H. J., Doisy, E. A., Jr., Elliott, W. H., Thayer, S. A., and Doisy, E. A. Synthesis and biological studies of 17 -methyl- $\mathrm{C}^{14}$ estradiol. J. biol. Chem. 1953, 202, 27.

3. Bocklage, B. C., Doisy, E. A., Jr., Elliott, W. H., and Doisy, E. A. Absorption and metabolism of cortisone-4-C $\mathrm{C}^{14}$-acetate. J. biol. Chem. 1955, 212, 935.

4. Hellman, L., Bradlow, H. L., Frazell, E. L., and Gallagher, T. F. Tracer studies of the absorption and fate of steroid hormones in man. J. clin. Invest. 1956, 35, 1033.

5. Biggs, M. W., Friedman, M., and Byers, S. O. Intestinal lymphatic transport of absorbed cholesterol. Proc. Soc. exp. Biol. (N. Y.) 1951, 78, 641.

6. Chaikoff, I. L., Bloom, B., Siperstein, M. D., Kiyasu, J. Y., Reinhardt, W. O., Dauben, W. G., and Eastham, J. F. C $^{14}$-cholesterol; I. Lymphatic transport of absorbed cholesterol-4-C $\mathrm{C}^{14}$. J. biol. Chem. 1952, 194, 407.

7. Mueller, J. H. The mechanism of cholesterol absorption. J. biol. Chem. 1916, 27, 463.

8. Gallagher, T. F., Bradlow, H. L., Fukushima, D. K., Beer, C. T., Kritchevsky, T. H., Stokem, M., Eidinoff, M. L., Hellman, L., and Dobriner, K. Studies of the metabolites of isotopic steroid hormones in man. Recent Progr. Hormone Res. 1954, 9, 411.

9. Barry, M. C., Eidinoff, M. L., Dobriner, K., and Gallagher, T. F. The fate of $\mathrm{C}^{14}$-testosterone and $\mathrm{C}^{14}$-progesterone in mice and rats. Endocrinology 1952, 50, 587.

10. Bradlow, H. L., Dobriner, K., and Gallagher, T. F. The fate of cortisone- $T$ in mice. Endocrinology 1954, 54, 343.

11. Rosenfeld, R. S., Hellman, L., Considine, W. J., and Gallagher, T. F. Isolation of radioactive cholesterol from plasma. J. biol. Chem. 1954, 208, 73. 
12. Hellman, L., Rosenfeld, R. S., and Gallagher, T. F. Cholesterol synthesis from $\mathrm{C}^{\mathbf{1 4}}$-acetate in man. $\mathrm{J}$. clin. Invest. 1954, 33, 142.

13. Eidinoff, M. L. Measurement of radiocarbon as carbon dioxide inside Geiger-Müller counters. Analyt. Chem. 1950, 22, 529.

14. Eidinoff, M. L. Internal gas counting of radioactive carbon and hydrogen. A. I. E. E., 2nd Annual Joint Conf. on Electronics in Nucleonics and Medicine (Special Publication 33). New York, American Institute of Electrical Engineers, 1950, p. 65.

15. Swell, L., Trout, E. C., Jr., Hopper, J. R., Field, H., Jr., and Treadwell, C. R. Mechanism of cholesterol absorption; II. Changes in free and esterified cholesterol pools of mucosa after feeding cholesterol-4-C ${ }^{\mathbf{1 4}}$. J. biol. Chem. 1958, 233, 49.

16. Rosenfeld, R. S., and Hellman, L. The relation of plasma and biliary cholesterol to bile acid synthesis in man. J. clin. Invest. 1959, 38, 1334.

17. Hernandez, H. H., Chaikoff, I. L., and Kiyasu, J. Y. Role of pancreatic juice in cholesterol absorption. Amer. J. Physiol. 1955, 181, 523.

18. Hernandez, H. H., Chaikoff, I. L., Dauben, W. G., and Abraham, S. Absorption of $\mathrm{C}^{\mathbf{1 4}}$-labeled epicholesterol in the rat. J. biol. Chem. 1954, 206, 757.

19. Friedman, M., Byers, S. O., and Shibata, E. Observations concerning the production and excretion of cholesterol in mammals; factors affecting absorption and fate of ingested cholesterol. J. exp. Med. 1953, 98, 107.

20. Blomstrand, R., and Ahrens, E. H., Jr. Absorption of fats studied in a patient with chyluria; III. Cholesterol. J. biol. Chem. 1958, 233, 327.

21. Hellman, L., Rosenfeld, R. S., Eidinoff, M. L., Fukushima, D. K., Gallagher, T. F., Wang, C-I., and Adlersberg, D. Isotopic studies of plasma cho- lesterol of endogenous and exogenous origins. J. clin. Invest. 1955, 34, 48.

22. Bollman, J. L., and Flock, E. V. Cholesterol in intestinal and hepatic lymph in rat. Amer. J. Physiol. 1951, 164, 480.

23. Daskalakis, E. G., and Chaikoff, I. L. The significance of esterification in the absorption of cholesterol from the intestine. Arch. Biochem. 1955, 58, 373.

24. Swell, L., Flick, D. F., Field, H., Jr., and Treadwell, C. R. Role of fat and fatty acids in absorption of dietary cholesterol. Amer. J. Physiol. 1955, 180, 124.

25. Swell, L., Boiter, T. A., Field, H., Jr., and Treadwell, C. R. Pantothenate and dietary cholesterol in the maintenance of blood and tissue cholesterol esters. J. Nutr. 1955, 27, 121

26. Swell, L., Boiter, T. A., Field, H., Jr., and Treadwell, C. R. Absorption of dietary cholesterol esters. Amer. J. Physiol. 1955, 180, 129.

27. Swell, L., Flick, D. F., Field, H., Jr., and Treadwell, C. R. Influence of dietary bile salts on blood cholesterol levels. Proc. Soc. exp. Biol. (N. Y.) 1953, 84, 428.

28. Swell, L., Byron, J. E., and Treadwell, C. R. Cholesterol esterases; cholesterol esterase of rat intestinal mucosa. J. biol. Chem. 1950, 186, 543.

29. Morris, H. Human Anatomy, 11th ed., J. P. Schaeffer, Ed. New York, Blakiston, 1953, p. 863.

30. Byers, S. O., and Friedman, M. Observations concerning the production and excretion of cholesterol in mammals; role of pancreas in absorption of cholesterol. Amer. J. Physiol. 1955, $182,69$.

31. Favarger, P., and Metzger, E. F. La résorption intestinale du deutério-cholésterol et sa répartition dans l'organisme animal sous forme libre et estérifiée. Helv. chim. Acta 1952, 35, 1811. 